\title{
Çok Kriterli Karar Verme Yöntemlerinin Gemi İnşaatı ve Gemi Makineleri Mühendisliğinde Uygulamaları
}

\author{
Salim Tamer ${ }^{1}$, Barış Barlas ${ }^{2}$, Sefer Anıl Günbeyaz ${ }^{3}$ \\ 1,2 Gemi İnşaatı ve Deniz Bilimleri Fakültesi, Gemi İnşaatı ve Gemi Makineleri Mühendisliği Bölümü, i̇stanbul Teknik \\ Üniversitesi, İstanbul, Türkiye \\ ${ }^{3}$ Mühendislik Fakültesi, Gemi İņ̧aatı, Deniz Bilimleri ve Gemi Makineleri Mühendisliği Bölümü, Strathclyde \\ Üniversitesi, Glasgow, United Kingdom \\ ${ }^{1}$ (sorumlu yazar), stamer@itu.edu.tr, ORCID: 0000-0003-2939-5758 \\ 2 barlas@itu.edu.tr, 0000-0002-5846-2369 \\ 3 sefer.gunbeyaz@strath.ac.uk,0000-0002-5624-1845
}

\section{ÖZET}

Tüm mühendislik alanlarında olduğu gibi gemi inşaatı ve gemi makineleri mühendisliğinde de karar verme süreçleri önemlidir. Karar vermenin en çok uygulanan dalı ise, nitel ve nicel faktörleri birlikte içeren, çok kriterli karar vermedir. Bu çalışmada, çok kriterli karar verme (MCDM) yöntemlerinin gemi inşaatı ve gemi makineleri mühendisliğinde uygulamaları 21 Türkçe lisansüstü tezi, 21 İngilizce uluslararası makale ile incelenmiştir. En sık başvurulan MCDM yönteminin, ilk önce AHP ve sonrasında TOPSIS olduğu, en sık kullanım amacının ise ilk önce gemi sistemleri seçimi ve sonrasında gemi dizaynı olduğu tespit edilmiştir. Yöneylem araştırmasının bir alt alanı olan MCDM, konuya yeni giriş yapmak isteyen gemi inşaatı ve gemi makineleri mühendisleri için sunulmuştur. Bu çalışma ile araştırmacılara, tespit ettikleri özgün MCDM problemlerine, özgün MCDM yaklaşımları getirmelerine yardımcı olmak amaçlanmıştır.

Anahtar kelimeler: karar verme, çok kriterli karar verme, gemi inşaatı ve gemi makineleri mühendisliği, ÇKKV, MCDM derleme

Makale geçmişi: Geliş 12/06/2021 - Kabul 15/11/2021

https://doi.org/10.54926/gdt.951401 


\title{
Applications of Multi-Criteria Decision-Making Methods in Naval Architecture and Marine Engineering
}

\author{
Salim Tamer ${ }^{1}$, Barış Barlas ${ }^{2}$, Sefer Anıl Günbeyaz ${ }^{3}$ \\ ${ }^{1,2}$ Faculty of Naval Architecture and Ocean Engineering, Department of Naval Architecture and Marine \\ Engineering, Istanbul Technical University, Istanbul, Turkey \\ ${ }^{3}$ Faculty of Engineering, Department of Naval Architecture, Ocean and Marine Engineering, University of \\ Strathclyde, Glasgow, United Kingdom \\ ${ }^{1}$ (corresponding author), stamer@itu.edu.tr, ORCID: 0000-0003-2939-5758 \\ 2 barlas@itu.edu.tr, 0000-0002-5846-2369 \\ 3 sefer.gunbeyaz@strath.ac.uk, 0000-0002-5624-1845
}

\begin{abstract}
Decision-making processes are important in naval architecture and marine engineering, similar to all engineering fields. The well-known branch of decision making is the Multi-Criteria Decision Making (MCDM) which involves both quantitative and qualitative factors. In this study, the applications of MultiCriteria Decision Making (MCDM) methods in naval architecture and marine engineering were examined with 21 Turkish postgraduate theses and 21 English international articles. It is find out that the most frequently used MCDM method is firstly AHP and secondly TOPSIS, and the most frequently used purpose is firstly ship systems selection and secondly ship design. MCDM, a sub-field of operations research, is presented for naval architecture and marine engineers who are new and inexperienced to the subject. With this study, one another aim is to help researchers to bring original MCDM approaches to the original MCDM problems.
\end{abstract}

Keywords: Decision-making, multi-criteria decision-making, naval architecture and marine engineering, MCDM, MCDM literature review

Article history: Received 12/06/2021 - Accepted 15/11/2021 


\section{Giriş}

Karar verme, bilimsel, sosyal ve ekonomik açıdan en önemli konulardan biridir (Ross, 2004). Muhtemelen, bilim ve mühendislik alanında en sürekli tartışmalardan biri, belirli bir durumda en uygun kararın nasıl verileceğidir (Triantaphyllou, 2000).

Eski uygarlıklarda insanlar, önemli kararları almadan önce din adamlarından ya da bilge kişilerden tavsiye alırlardı. Tüm bu eski uygarlıkların üzerinden yüzyıllar geçti ve bu eski yöntemlerin yerini, günümüzde gelişen bilim ve teknoloji aldı. Yaşamdaki çoğu durum, bir veya diğer biçimdeki karar süreçlerini içerir, sabah uyandığımız andan günün sonunda bedenlerimizin dinlendirileceğimiz zamana kadar birçok sayıda karar verilir.

Ancak, çoğu zaman karar alma sürecini etkileyen bilgiler muhtemelen eksik veya belirsizdir; bu nedenle sonuçlar belirsizdir (Ross, 2004). Belirsizlik altında karar verme ile uğraşırken, iyi bir karar ile iyi bir sonuç arasında belirgin bir farklıık olduğunu unutmamalıdır. İyi bir kararın sonucu olumsuz olabilir ya da kötü bir karar verebiliriz ve sonuç olumlu olabilir. Uzun vadede, sürekli olarak iyi kararlar verirsek, avantajlı durumlar kötü olanlardan daha sık meydana gelir (Ross, 2004). Belirsiz bir dünyada, sorumlu karar verici, olası sonuçlar için kendi tercihi ile belirsizlikler arasındaki yargıları dengelemelidir (Keeney vd., 1993).

Literatürün çoğu, ekonomik ve finansal riskler karşısında karar verme konusuna değinirken, mühendisler öncelikle iki tür kararla ilgilidir (Maes ve Faber, 2004): (1) mevcut kaynaklarla optimal bir işlem yapılması gereken operasyonel kararlar ile belirli bir tehlikelerden kaçınmak ve (2) birinin gelecekteki olayların hazırlık derecesi veya beklenti düzeyine ilişkin kararları içeren stratejik kararlar.

Bu çalışmada, gemi inşaatı ve gemi makineleri mühendisliği alanında yapılmış olan çok MCDM yöntemleri uygulamaları incelenmiştir. MCDM, gemi inşaatı ve gemi makineleri mühendisliğinin temel lisans seviyesinde öğretilen bir konusu değildir, bu çalışma sayesinde konuya yabancı olan mühendislere bir tanıtım ve konuya yumuşak bir giriş yapma amacı güdülmüştür. Ülkemizde ve uluslararası ölçekte MCDM yöntemleri 2000'li yıllarla birlikte sıkça uygulanmıştır. MCDM yöntemlerine olan bu ilgiden, gemi inşaatı ve gemi makine mühendisliği alanı da etkilenmiştir. Bu çalışmanın bir diğer amacı, araştırmacılara, özgün MCDM problemleri tespit etmelerine ve bu problemlerin çözümünde özgün MCDM yöntemlerini kullanmalarına yardımcı olmaktır.

\section{2. Çok Kriterli Karar Verme (MCDM)}

"Kriter" için sözlük tanımı "yargılamanın bir yolu ya da standardıdır". Karar verme bağlamında, bu, belirli bir seçimin veya hareket tarzının diğerinden daha arzu edilir olduğuna karar verilebilecek bir tür standart anlamına gelir. Önemli ölçüde çelişen bu tür bir dizi standart olduğunda, farklı eylem tarzı seçeneklerinin dikkate alınması, MCDM problemini oluşturur (Belton ve Stewart, 2002).

Çelişkili kriterler, seçeneklerin değerlendirilmesinde tipiktir: maliyet veya fiyat genellikle ana kriterlerden biridir ve bazı niteliksel ölçüler tipik olarak başka bir kriteri oluşturur ve maliyetle kolayca çelişir. Örneğin; bir araba satın alırken, maliyet, konfor, güvenlik ve yakıt ekonomisi göz önünde bulundurduğumuz ana kriterlerden bazıları olabilir - en ucuz arabanın en konforlu ve en güvenli olması alışılmadık bir durumdur (Url-1).

Çok kriterli problemlerin doğası, çoğu zaman farklı bakış açılarını yansıtan ve sıklıkla zamanla değişen, karmaşık ve çelişkili bir yapıya sahip çok fazla bilgi olmasıdır (Belton ve Stewart, 2002). MCDM 
yaklaşımlarının temel amaçlarından biri, karar vericilerin bu tür bilgileri, karar verme konusunda kendilerini rahat ve kendinden emin hissetmelerini sağlayacak şekilde organize etmelerine ve sentezlemelerine yardımcı olmaktır. Ayrıca, tüm kriterlerin veya faktörlerin uygun şekilde dikkate alındığından emin olarak karar sonrası oluşabilecek pişmanlığı en aza indirmeyi amaçlar.

Bu nedenle, bu çalışmada, MCDM ifadesini, bireylerin veya grupların önemli kararları keşfetmelerine yardımcı olmada çoklu kriterleri açık bir şekilde hesaba katmaya çalışan resmi yaklaşımların ve yöntemlerin bir arada tanımlamak için genel terim olarak sunulmuştur.

\section{3. Ülkemizde Yapılan Lisansüstü Tezleri}

Paksoy (1998) gemi seçim problemini, karmaşık ve yüksek maliyetlerin dâhil olduğu aynı zamanda nitel, nicel birçok amacın olduğu bir karar verme süreci olarak tanımlamıştır. Gemi seçim problemini AHP ve ELECTRE ile çözmüştür. Yaraş (1999), isimlerini ve unvanlarını liste halinde verdiği uzmanların görüşleri doğrultusunda, ticari gemilere ana makinası seçimi amacıyla karar matrisleri oluşturmuştur ve karar matrislerini TOPSIS ile analiz etmiştir. Menteş (2000), sevk ve manevra sistemi için üç adet alternatif sırasıyla, sabit hatveli pervane ve vec-twin dümen, dönebilir iticiler ve sikloidal pervane olarak belirlemiştir. Bu alternatifleri, Yager ve Chen'in bulanık MCDM yöntemleri ile değerlendirmiştir. Yager ve Chen'in yöntemlerini birbiriyle kıyaslamıştır.

Ölçer (2001) yeni bir bulanık öz-nitelikli karar verme yöntemi geliştirmiş ve iki adet vaka çalışmasına (sevk/manevra sistemi seçimi (Ölçer ve Odabaşı, 2005) ve gemi ana makine seçimine) uygulamıştır. Yeni yöntemin avantajı, bulanık bir ortamda çok öz-nitelikli grup karar verme problemlerinin çözümü için çok uygun bir yöntem olmasıdır ayrıca kullanımı ve anlaşılması çok kolay bir yöntem olup bilgisayarda kodlanması da, adımlar halinde tanımlanmış algoritması sayesinde oldukça basittir. Erdem (2002) savaş gemilerinin maliyetlerinin azaltılmasında bilgi yönetimi için bulanık çok öz-nitelikli karar verme yöntemini kullanmıştır. Bayar (2003), özel sektörün yatırım yaparken geleceğe yönelik karar vermekte zorlandığını vurgulamıştır ve öz değer fonksiyonu ile tanker seçimi için teknik özellikleri ve boyut gibi ölçütleri ile ağırlıklandırıp, TOPSIS ile sonuca gitmiştir.

Ata (2006), kıyıya yakın görev yapabilen savaş gemisi tasarım kriterlerinin ağırlıklarını AHP ile hesaplamıştır. Çiçek (2007), dizayn edilen alternatif konsept tekneler ve özelliklerini, karar vericilere değerlendirme yapabilmesini sağlayacak şekilde yer vermiştir. Çalışmanın sonuç bölümünde teknelerle ilgili anket sonuçları TOPSIS ile işlevsellik açısından değerlendirmiştir. Cengiz (2007), tersane yeri seçimi için ANP kullanmıştır. Saraçoğlu (2009) MCDM optimizasyonuna ve bulanık mantık temelli MCDM yöntemlerine dayalı yeni genel bir yöntem, yatırım analizlerinde kullanılabilmesi için sunmuştur. Bu çalışmada önerilen yöntemin gerçek yaşamdaki yatırım analizlerinde uygulanabileceğinin kanıtlanması için gemi inşaatı sektöründe vaka çalışması gerçekleştirmiştir. Menteş (2010) çok noktalı tanker-şamandıra bağlama sistemleri için en uygun bağlama sisteminin seçiminde, bulanık MCDM tabanlı bir yöntem geliştirmiştir. Bu yöntem, probleme uygun hiyerarşi ağacının kurulması, öz niteliklerin değerlendirilmesi, en uygun bağlama sisteminin seçimi ve tercihlerin sıralanması aşamalarında bulanık AHP ve bulanık TOPSIS yöntemlerini kullanan melez bir yapıya oluşturmuştur. Kırdağlı (2010), ülkemiz tersanelerinde verimliliği etkileyen parametrelerin belirlenmesi ve bunların bulanık AHP ile analizinin yapılması hedeflemiştir. Keçeci (2010), İstanbul Boğazı'nda gemi boyu faktörünün güvenli seyre olan etkisi incelenerek Boğaz geçişi yapan gemiler için büyük gemi boyunun araştırmıştır. İstanbul Boğazı'nda görev yapmakta olan uzman kişiler ile anket 
çalışması gerçekleştirilmiş ve Boğaz'daki tehlike etkenleri hakkında bilgi edinmiştir. Sayısal değerler elde etmek maksadıyla AHP yöntemi kullanılarak sonuç almaya çalışmıştır.

Kafalı (2014), bulanık karar verme yöntemleri kullanılarak gemi inşa sanayisinin iki konusunu ele almıştır. Bunlardan ilki tersaneler için uygun boru kesim teknolojisi seçimi diğeri ise armatörlerin yeni gemi inşa tersanesi seçimidir. Boru kesim teknolojisi olarak bulanık AHP ve bulanık TOPSIS içeren bütünleşik bir yöntem ile plazma kesim en uygun yöntem olarak belirlemiştir (Kafalı vd., 2014). íkinci konu olan yeni gemi inşası için tersane seçiminde kriterleri bulanık AHP ile derecelendirmiş ve yeni gemi inşası için teklif fiyatı, üretilmiş benzer gemi sayısı ve ödeme koşulları en çok önem verilen ilk üç kriter olarak tespit etmiştir (Kafalı ve Özkök, 2015). Erol (2014), gemi seçim problemini, gemi inşa sektöründe görev alan üst düzey yöneticilerden oluşan karar vericilerle yapılan görüşmeler sonucu, alternatif olarak ifade edilen gemi tipleri dilsel ifadeler yardımıyla ayrı ayrı değerlendirmiş ve daha sonra bu değerlendirmeler üçgen bulanık sayılar kullanılarak TOPSIS ve VIKOR yöntemleri yardımıyla sayısal olarak analizi yapmış ve sonuçlar karşılaştırmıştır. Uzun (2015), toplam on iki kriter ile NB 25 Wartsila balıkçı gemisi projesine uygun ana makine ve jeneratör seçimi problemi, AHP, TOPSIS ve PROMETHEE yöntemleriyle çözüm getirilmeye çalışmış ve bulunan sonuçlar karşılaştırmıştır.

Ünver (2017), iki zamanlı gemi dizel makinelerinde yapılan bakım-onarım faaliyetleri risk büyüklükleri açısından incelemiş, en riskli bakım-onarım faaliyetleri belirlemeye çalışmıştır. Bulanık AHP yöntemi 46 bakım-onarım çalışması, Buckley ve Chang yaklaşımları ile karşılaştırmış ve risk ağırlıkları tespit etmiştir. Balbaş (2019), tersanelerin dünya pazarındaki rekabet ortamında başarılı olabilmelerini sağlamada, projenin başlangıcından bitimine kadar olan bütün karar verme süreçlerinde uygulayabilecekleri MCDM yöntemlerinden bulanık AHP ve bulanık TOPSIS yöntemlerini kullanarak, özel bir tersanenin inşa edebileceği ideal gemi tipini belirleme uygulaması yapmıştır. Akın (2020), kapasite ve işleyiş bakımından farklı üç adet tersaneden gerçek iş kazası ve ramak kala olay verilerini almış AHP yöntemi ile ağılıklandırmış ve tersanelerin risk analizi için mevcut her bir tehlikenin riskini ve genel risk seviyesi ortaya koyacak gerçekçi bir yöntem geliştirmiştir. Güler (2020), gemi inşa projelerinde verimliliği artırmak için kullanılacak PLM yazılımının seçilmesi için AHP yöntemi ile en uygun yazılıma karar vermiştir.

Kahvecioğlu (2021), bir gemi için balast arıtma sistemi finansal ve operasyonel koşullar dikkate alınarak araştırmıştır ve değerlendirilmesi için 7 farklı balast arıtma sistemi üzerine incelemeler yaptı, gemi için karar verilirken uygulanabilirlik, teknik, ekonomik ve bunların alt kriterleri derecelendirilerek çok kriterli bir karar verme modeli oluşturularak optimum seçeneği belirlemiştir.

\section{1. Ülkemizde Yapılan Çalışmaların Değerlendirmesi}

Bu derleme çalışma kapsamında 21 lisansüstü tezi YÖK TEZ veri tabanından taranmıştır. Anahtar kelimeler olarak "çok kriterli karar verme" ve "gemi" veya "tersane" kullanılmıştır. Sonuçlar tek tek incelenerek gemilerin işletilmesi ile ilgili olan deniz ulaştırma ve işletme mühendisliği ve gemi makinaları işletme mühendisliği alanına giren yayınlar dışarıda tutulmuştur. Hassas bir tarama ve eleme süreci sonunda belirlenen, 21 lisansüstü tezinin 6 tanesi doktora tezi, geri kalan 15 tanesinin yüksek lisans tezidir. Çalışmalardan 10 tanesi bulanık mantık temelini içeren MCDM yöntemlerle çözüm ararken, 11 tanesi bulanık olmayan MCDM yöntemleriyle seçtikleri problemi çözmüştür.

21 adet tezde hangi yöntemin kullanıldığı aşağıda sunulmuştur.

$\checkmark 4$ çalışmada AHP, 
ISSN: 1300-1973, e-ISSN: 2651-530X, Journal homepage: http://www.gmoshipmar.org/

3 çalışmada TOPSIS,

$\checkmark \quad 3$ çalışmada bulanık AHP ve bulanık TOPSIS

$\checkmark 2$ çalışmada bulanık AHP

$\checkmark 1$ çalışmada ANP

$\checkmark \quad 1$ çalışmada bulanık TOPSIS ve bulanık VIKOR

$\checkmark 1$ çalışmada AHP, TOPSIS ve VIKOR

$\checkmark 1$ çalışmada bulanık Yager ve Chen

$\checkmark 1$ çalışmada AHP ve ELECTRE

$\checkmark 1$ çalışmada belirtilmemiş bulanık MCDM

$\checkmark 1$ çalışmada belirtilmemiş MCDM

$\checkmark 2$ çalışmada ise araştırmacılar kendilerine ait yeni bulanık MCDM yöntemini uygulamıştır.

Belirtilen yöntemlerin hangi amaçla kullanıldığı aşağıda sunulmuştur.

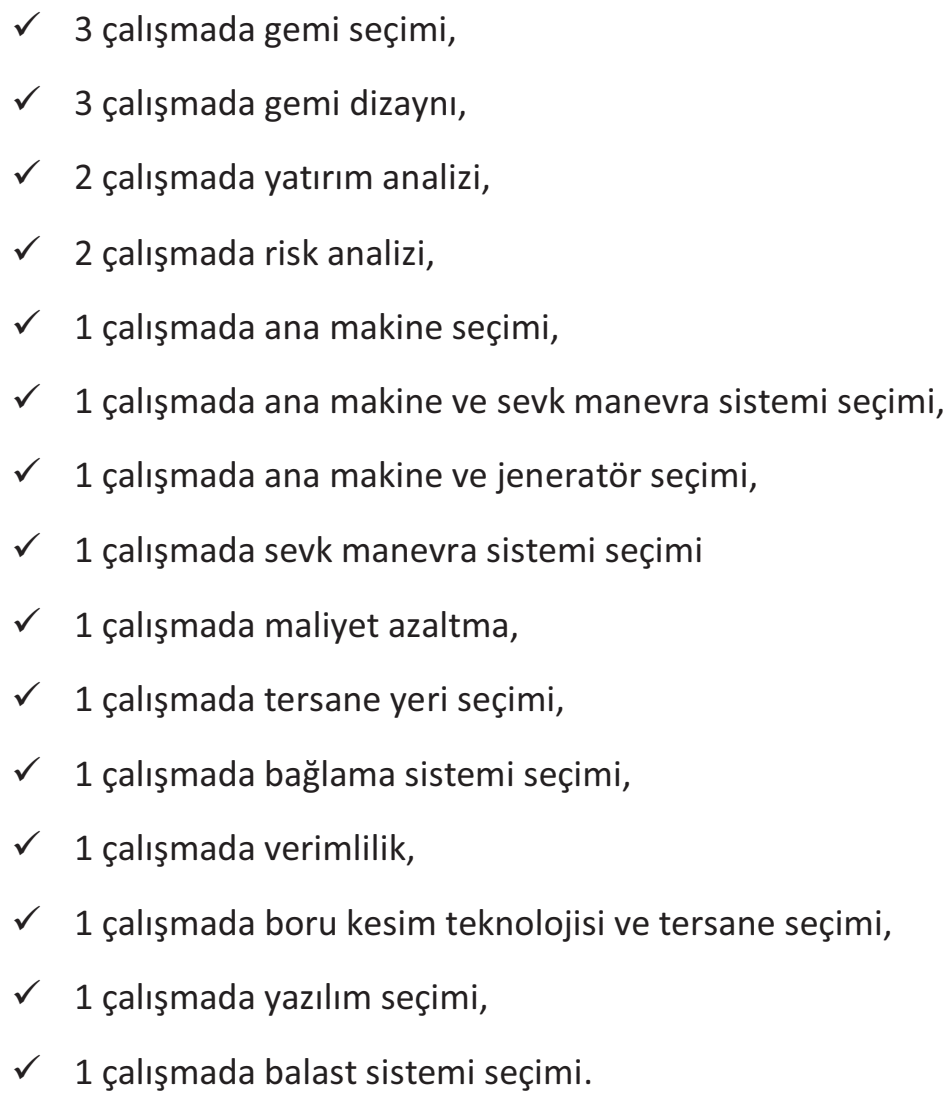

Ülkemizde gemi inşaatı ve gemi makineleri mühendisliği alanında MCDM yöntemlerinin geniş kapsamlı bir şekilde uygulandığı görülmektedir. Yöntem bazında değerlendirecek olursak, AHP yönteminden 21 çalışmanın 13'ünde kullanıldığı görülmektedir. İkinci olarak en sık başvurulan yöntem, 6 çalışma ile TOPSIS yöntemi gelmektedir. Ayrıca MCDM yöntemlerinin hangi amaçlarla kullanıldığını inceleyecek olursak, 21 çalışmanın 6'sında gemi sistemlerinin seçimi yapılmış ve 3 çalışmada gemi seçimine, 3 çalışmada ise gemi dizaynı amacıyla kullanılmıştır. 


\section{Uluslararası Makaleler}

Ölcer vd. (2006), çok amaçlı optimizasyonu, bulanık çok nitelikli grup karar verme tekniğine dahil eden yeni bir MCDM metodoloji sunmuşlardır ve yaklaşımın doğruluğunu göstermek için gerçek Ro-Ro gemisinin altbölümlerinin planlanmasına uygulamışlardır. Güneri vd. (2009) yatırımcılar için, finansal bir karar olan tersane yeri seçiminde bulanık mantık ile beraber ANP'yi kullanmışlardır ve diğer kritik kararları alma süreçleri yöntemi önermişlerdir. Çelik vd. (2009) gemi bakımı için önemli bir faaliyet olan havuzlama faaliyetleri için tersane seçimini, çok kriterli bulanık aksiyomatik dizayn ile gerçekleştirmişlerdir. Matulja vd. (2009) tersane yerleşimi için alternatif yerleşimleri sıralamada AHP yöntemini kullanmışlardır.

Zangoueinezhad vd. (2011) bulanık AHP ve bulanık TOPSIS yaklaşımını, gemi inşaat endüstrisi için tedarikçi seçimi problemine ve rekabetçiliğine göre tedarik zinciri sıralamasına uygulamışlardır. Barlas (2012), 20002011 yılları arasındaki Türk tersanelerinde, iş kazası kaynaklı ölümleri AHP yaklaşımıyla incelemiştir. Zapata Cortés vd. (2012), birçok niteliksel ve niceliksel faktör gerektiren lojistik yazılımı tercihini, Kolombiya tersanesi için Chang'ın 1996'da sunduğu bulanık genişletilmiş AHP ile yapmışlardır. Yang vd. (2012), denizlerde hava kirliliğine neden olan gemi kaynakıı NOx ve SOx gazlarının salınımı kontrol yöntemlerini, AHP ve TOPSIS ile değerlendirmişlerdir. Balin vd. (2015) bulanık AHP ve bulanık VIKOR hibrit yöntemini, gemi ana makine yardımcı sistemlerinde arıza tespiti için kullanmışlardır.

Çebi vd. (2016) gemi inşaatı endüstrisinde kullanılan en uygun çelik kesim tekniğini bulanık AHP, bulanık bilgi aksiyomu ve TOPSIS içeren bir entegre MCDM ile Oxy-Fule çelik kesim teknolojisi olarak göstermiş̧lerdir. Balin vd. (2016) gemi sevk sisteminde de kullanılabilen gaz tribünlerinde arızaları bulanık AHP ve TOPSIS ile analiz etmişlerdir. Lazakis ve Ölçer (2016) bir cruise gemisinde dizel jeneratör sisteminin bakımı için düzeltici bakım, öngörücü bakım ve koruyucu bakım alternatiflerini, bulanık küme teorisini AHP yöntemine dâhil eden bir MCDM yöntemiyle incelemişlerdir ve öngörücü bakımı en iyi alternatif olarak belirlemişlerdir. Mytilinou vd. (2018) Birleşik Krallık'ta maliyet olarak en karlı açık deniz rüzgar çiftliği yatırımı yapılacak bölgeyi tespit etmek amacıyla TOPSIS ve genetik algoritmanın dahil olduğu bir çalışma yapmışlardır. Ebrahimi vd. (2018) bir veri analizi ve MCDM kullanarak cruise gemilerinin konsept dizayn zorluklarını çözümlemişlerdir. Jeong vd. (2018) maliyet, çevrecilik ve risk açısından bir gemi için dizel elektrikli sevk sisteminin mi yoksa konvensiyonel sevk sisteminin mi tercih edilmesi gerektiğini yeni bir MCDM yöntemiyle araştırmışlardır. Demirel (2020) cruise gemilerinde konfor, güvenlik ve hız gibi birçok kriteri etkileyen stabilizatör tercihi için bulanık mantığın dâhil edildiği TOPSıS ile MCDM analizi yapmıştır ve aktif fin stabilizatör sistemini en etkili sistem olarak tespit etmiştir. Demirel vd. (2020) stabilizatör seçim problemini bu sefer bir motor yat için melez AHP ve VIKOR ile gerçek bir vaka çalışması temelinde incelemişlerdir. Jafaryeganeh vd. (2020) $234 \mathrm{~m}$ boyunda bir shuttle petrol tanker gemisinin iç kompartıman yerleşimini analizini kıyaslamalı bir çalışma ile ilk olarak Pareto yöntemiyle belirlenen alternatiflere son seçim aşaması için ağılıklı toplam, ağırlıklı çarpım, TOPSIS ve ELECTRE yöntemleriyle uygulamışlardır. İnal ve Deniz (2020), IMO sera gazlarının salınımını azaltmak için çeşitli kurallar ve kısıtlamalar getirmekte olduğunu belirtmişlerdir, bu bağlamda ticari gemilerde kullanılabilen 5MW'a kadar ana makine gücü üretebilen yakıt pillerini AHP yöntemiyle sıralamışlardır. Türk ve Özkök (2020), tersane yeri seçimi, birbiriyle çelişen, sayısal ve sözel kriterler içeren bir karar olduğunu söylemişlerdir, bulanık AHP ve bulanık TOPSIS birleşimi bir MCDM yöntemi olası tersane yerlerini sıralaması için önermişlerdir ve sunulan yöntem Türkiye'de tesis yeri seçimi problemi özelinde tersane yeri seçimi için uygulamışlardır. 
ISSN: 1300-1973, e-ISSN: 2651-530X, Journal homepage: http://www.gmoshipmar.org/

Caner ve Aydın (2021), AHP yöntemiyle tersane yeri için coğrafik bilgi sistemi kapsamında İskenderun, Türkiye bölgesi için bir araştırma yapmışlardır ve sonuç olarak çıkan tersane yerinin hali hazırda liman olarak hizmet vermekte olduğunu fark etmişlerdir.

\subsection{Uluslararası Çalışmaların Değerlendirmesi}

Bu derleme çalışma kapsamında 21 uluslararası makale WEB OF SCIENCE veri tabanından taranmıştır. Anahtar kelimeler olarak, "multiple criteria decision making" ve "naval architecture" kullanılmıştır. Çıkan sonuçlar tek tek incelenmiştir. 21 makalenin 10'unda bulanık mantık temelli yöntemler kullanılırken, 11 'inde bulanık olmayan yöntemler kullanılmıştır.

21 adet makalede hangi yöntemin kullanıldığı aşağıda sunulmuştur.

$\checkmark \quad 4$ makalede AHP

$\checkmark \quad 2$ makalede bulanık AHP ve TOPSIS

$\checkmark \quad 2$ makalede bulanık AHP ve bulanık TOPSIS

$\checkmark \quad 2$ makalede bulanık AHP

$\checkmark \quad 1$ makalede bulanık AHP ve bulanık VIKOR

$\checkmark \quad 1$ makalede melez AHP ve VIKOR

$\checkmark \quad 1$ makalede AHP ve TOPSIS

$\checkmark \quad 1$ makalede TOPSIS

$\checkmark \quad 1$ makalede bulanık TOPSIS

$\checkmark 1$ makalede ağırlıklı toplam, ağırlıklı çarpım, TOPSIS ve ELECTRE

$\checkmark \quad 1$ makalede ANP

$\checkmark 1$ makalede bulanık aksiyomatik dizayn

$\checkmark \quad 1$ makalede veri analizi ve MCDM

$\checkmark \quad 1$ makalede yeni bulanık MCDM

$\checkmark \quad 1$ makalede yeni MCDM

Belirtilen yöntemlerin hangi amaçla kullanıldığı aşağıda sunulmuştur.

$\checkmark \quad 3$ makalede dizayn

$\checkmark \quad 3$ makalede tersane yeri seçimi

$\checkmark \quad 2$ makalede arıza tespiti

$\checkmark \quad 2$ makalede stabilizör seçimi

$\checkmark \quad 1$ makalede tersane yerleşimi seçimi

$\checkmark 1$ makalede tersane seçimi

$\checkmark 1$ makalede tedarikçi seçimi 


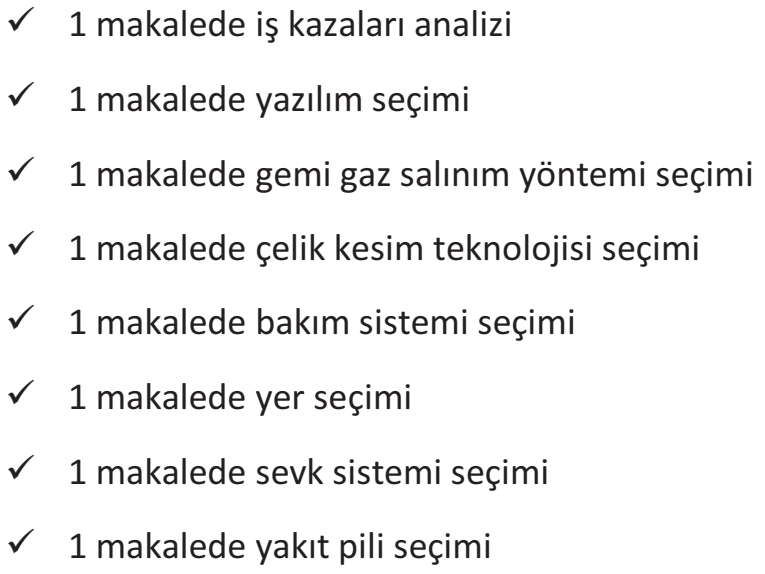

Uluslararası ölçekte gemi inşaatı ve gemi makineleri mühendisliği alanında MCDM yöntemlerinin geniş kapsamlı bir şekilde uygulandığı görülmektedir. Yöntem bazında değerlendirecek olursak, AHP yönteminden 21 makalenin 13'ünde kullanıldığı görülmektedir. İkinci olarak en sık başvurulan yöntem, 8 makale ile TOPSIS yöntemi gelmektedir. Ayrıca MCDM yöntemlerinin hangi amaçlarla kullanıldığını inceleyecek olursak, 21 çalışmanın 5'inde gemi sistemlerinin seçimi yapılmış ve 3 çalışma gemi dizaynı, 3 çalışmada ise tersane yeri seçimi amacıyla kullanılmıştır.

\section{Tartışma}

Belirli kısıtların olduğu bir durumda, belirli bir amaca yönelik en uygun çözümün bulunması için "yöneylem araştırması" (operations research); geliştirilmiştir. Yöneylem araştırması; bir organizasyon içinde operasyonların koordinasyonu ve yürütmesi ile ilgili dünyanın gerçek karmaşık sorunları için fikir üretmede matematiksel modelleme, istatistik ve algoritma gibi bilimsel yöntemleri kullanan disiplinler arası bir bilimdir(Url-2). MCDM ise, karar vericiler tarafından performans kriterlerinin subjektif değerlendirmesini desteklemek için hesaplamalı ve matematiksel araçlar tasarlamakla ilgilenen yöneylem araştırmasının bir parçası olarak gelişmiştir. MCDM yöntemleri, en iyi alternatifleri seçmek için birçok alana uygulanmıştır.

Bu çalışmada, 42 adet Türkçe ve İngilizce çalışma incelenmiştir. Derleme çalışmada iki önemli soruya cevap aranmıştır; (1) hangi MCDM yöntemi kullanıldı?; (2) hangi amaçla MCDM analizi yapıldı?

Illk sorunun cevabı; 26 çalışmada AHP yöntemini içeren MCDM yöntemleri kullanılmıştır. İkinci olarak en fazla uygulanan yöntem ise 14 çalışma ile TOPSIS içeren çalışmalar olmuştur. Sadece gemi inşaatı ve gemi makineleri mühendisliği alanında değil, genel olarak en sık başvurulan iki MCDM yöntemi sırasıyla AHP ve TOPSIS'tir (Mardini vd., 2015). AHP, matematik ve psikolojiye dayalı karmaşık kararları organize etmek ve analiz etmek için yapılandırılmış bir tekniktir, 1970'lerde Thomas L. Saaty tarafından geliştirilmiştir (Url-3). O zamandan beri AHP çokça uygulanmıştır. Açık literatürde AHP ile ilgili birçok kaynak kolaylıkla bulunabilmektedir. AHP, kullanıcıların ağırlıkları dağıtırken belirli kriterlere ve alt kriterlere daha iyi odaklanmasını sağlayan hiyerarşik bir yapıya izin verme avantajına sahiptir (Ishizaka ve Labib., 2009). TOPSIS ise, ilk olarak 1981 'de Ching-Lai Hwang ve Yoon tarafından geliştirilmiştir (Url-4). TOPSIS yönteminin avantajlarından bazıları şunlardır: basitlik, rasyonellik, anlaşılabilirlik, iyi hesaplama verimliliği ve basit bir matematiksel formda her alternatif için göreceli performansı ölçme yeteneğidir (Roszkowska, 2011). 
İkinci sorunun cevabı; MCDM yöntemleri en çok 11 çalışma ile gemi sistemleri seçimine uygulanmıştır. Gemi sistemleri; ana makine, sevk manevra sistemi, jeneratör, bağlama sistemi, balast sistemi, stabilizör, gemi gaz salınım yöntemi ve yakıt pili seçimini kapsamaktadır. İkinci olarak en sık uygulandığı alan 6 çalışma ile gemi dizaynıdır.

\section{Sonuçlar}

MCDM, hem nicel hem de nitel faktörleri içeren kompleks bir karar verme süreci olarak kabul edilir. Aynı zamanda, birden fazla çelişkili kriterin olduğu durumlarda, insanların tercihlerine göre karar vermelerine yardımcı olan yöntemleri kapsar. Köksalan vd. (2011) MCDM yöntemlerinin tarihsel gelişimini bir kitapta sunmuşlardır.

MCDM ile analiz yapılırken, ilk önce, belirlenen kriterler, bir katsayı ile çarpılır, bu işleme literatürde ağırlıklandırma(weighing) denmektedir. Daha sonra, ağırlıklandırılmış bu kriter değerlerinin toplanması gerekir. Toplama işlemine uluslararası literatürde "aggregation" denmektedir. Bu süreçlerin içeriği kullanılan MCDM yöntemine göre farklılık gösterir.

\subsection{Katkıları neler?}

Bu çalışmada, ilk önce karar verme konusu tanıtılmıştır. Daha sonra MCDM'nin ne olduğundan bahsedilmiştir. Gemi inşaatı ve gemi makineleri mühendisliği özelinde kapsamlı bir literatür taraması yapılmıştır. Türkçe literatür taranırken YÖK TEZ veri tabanı, İngilizce literatür taranırken WEB OF SCIENCE veri tabanından faydalanılmıştır. Gemi inşaatı ve gemi makineleri mühendisliği alanında 2000li yıllar sonrası MCDM yöntemleri ve uygulamaları ile çok sayıda araştırma yapılmıştır. Gemi inşaatı ve gemi makineleri mühendisleri tarafından gemi sistemleri seçimi ve gemi üretimi alanlarında MCDM yöntemlerinin uygulamaları yapılmıştır. Her makalede kendine ait bir MCDM yöntemi seçilmiştir. Tüm bu makalelerde, en iyi alternatifleri bulmada her yöntemin kendine has özellikleri olduğu farklı uygulamalar için farklı yöntemler kullanılmıştır. Özetleri sunulan gemi inşaatı ve gemi makineleri mühendisliğine ait MCDM uygulamaları gelecekte MCDM uygulamalarını yapmak isteyen özellikle öğrenciler ve akademisyenler için derlenmiştir.

\subsection{Sınırlılıkları neler?}

Bu çalışma bazı sınırılıklara sahiptir. YÖK TEZ veri tabanından tarama yapılırken, "çok kriterli karar verme" ve "gemi" veya "tersane" kelimeleri girişmiştir. Çıkan çok sayıda tez, özetleri okunarak ilk elemeye tabi tutulmuştur. Bu işlem sırasında bazı tezlerin yanlış kategorilendirilebileceği unutulmamalıdır. Aynı şekilde uluslararası literatür taranırken "multiple criteria decision making" ve "naval architecture" anahtar kelimeleri girilmiştir. Arama motoru olarak GOOGLE SCHOLAR kullanılmıştır. Burada GOOGLE SCHOLAR arama motorunun sağladığı sonuçlara güvenilmiştir. Ancak girilen anahtar kelimeler ile tanımlanmamış makalelerin olabileceği unutulmamalıdır. Ayrıca WEB OF SCIENCE veri tabanına girmeyen makale ve bildiriler dışarıda tutulmuştur. Uluslararası tezlerin çalışmaya dâhil edilmemesi bir başka sınırlııktır.

Mardani (2015), 2000-2014 yılları arası MCDM yöntemlerinin yıllara göre logaritmik olarak arttığını tespit etmiştir. Mardani (2015) sonrası kapsamlı bir literatür taraması bulunmamaktadır. Mardini vd. (2016) uluslara göre MCDM yöntemlerinin uygulanma oranlarını incelemişlerdir. \%21,26 ile Tayvan MCDM 
yöntemlerinin en çok uygulandığı ülkedir. Hemen arkasından \%12,21 ile Türkiye ve \%11,19 ile İran gelmektedir.

\section{3. Öneriler neler?}

MCDM yöntemlerinin en önemli avantajı, farklı çelişen çıkarların işaret ettiği sorunları ele alma yetenekleridir, bu teknikleri kullanarak karar vericiler, yaygın optimizasyon modelleri kullanılarak çözülmesi mümkün olmayan problemleri çözebilirler (Mardini vd., 2015).

Huber vd. (2019), 10 bölümden oluşan kitaplarında, her bölümde MCDM ile ilgili yürütülen ayrı birer vaka çalışmasını sunmuşlardır. Araştırmacılar, bu vaka çalışmaları ve sunulan açık kaynak kodları kullanarak kendi alanlarına özgü problemlere uyarlayabilirler.

\section{Kısaltmalar}

AHP - Analytic hierarchy process

ANP - Analytic network process

CNC - Computer Numerical Control

DM - Decision-making

ELECTRE - Elimination and Choice Expressing Reality

FAD - Fuzzy Axiomatic Design

FMCDM - Fuzzy Multi-Criteria Decision-Making

MCDM - Multi-Criteria Decision-Making

PLM - Product Lifecycle Management

PROMETHEE - Preference Ranking Organization Method for Enrichment Evaluations

TOPSIS - The Technique for Order of Preference by Similarity to Ideal Solution

VIKOR - VIseKriterijumska Optimizacijia I Kompromisno Resenje

\section{Referanslar}

Akın, G. C. (2020). İş Sağlığı Ve Güvenliği Risk Değerlendirme Süreci İçin Yeni Bir Yaklaşım: Tersane İsletmelerinde Uygulama, Doktora Tezi, İstanbul Aydın Üniversitesi, Lisansüstü Eğitim Enstitüsü, İstanbul.

Ata, A., (2006). Çok Kriterli Karar Verme Yöntemlerinin Savaş Gemisi Tasarımına Yönelik Kriterlerin Ağırlık Katsayılarının Belirlenmesinde Kullanımı, Yüksek Lisans Tezi, Marmara Üniversitesi, Fen Bilimleri Enstitüsü, İstanbul.

Balbaş, O. (2019). Tersanelerde İnşa Edilecek Gemi Tipi Seçiminde Çok Kriterli Karar Verme, Yüksek Lisans Tezi, Yıldız Teknik Üniversitesi, Fen Bilimleri Enstitüsü, İstanbul. 
Balin, A., Demirel, H., \& Alarçin, F. (2015). A hierarchical structure for ship diesel engine trouble-shooting problem using fuzzy AHP and fuzzy VIKOR hybrid methods. Brodogradnja: Teorija i praksa brodogradnje i pomorske tehnike, 66(1), 54-65.

Balin, A., Demirel, H., ve Alarçin, F. (2016). A novel hybrid MCDM model based on fuzzy AHP and fuzzy TOPSIS for the most affected gas turbine component selection by the failures. Journal of marine engineering \& technology, 15(2), 69-78.

Barlas, B. (2012). Occupational fatalities in shipyards: An analysis in Turkey. Brodogradnja: Teorija i praksa brodogradnje i pomorske tehnike, 63(1), 35-41.

Bayar, N. (2003). Dünya tanker piyasası ve Türkiye piyasa koşullarına uygun kimyasal tanker araştırması, Yüksek Lisans Tezi, Yıldız Teknik Üniversitesi, Fen Bilimleri Enstitüsü, İstanbul.

Belton, V. ve Stewart, T. (2002). Multiple criteria decision analysis: an integrated approach. Springer Science \& Business Media.

Caner, H. I. ve Aydın, C. C. (2021). Shipyard site selection by raster calculation method and AHP in GIS environment, İskenderun, Turkey. Marine Policy, 127, 104439.

Cengiz, M. (2007). Türkiye'deki Mevcut Koşulların Bulanık Analitik Ağ Süreciyle Değerlendirilerek Uygun Tersane Yeri Seçimi, Yüksek Lisans Tezi, Yıldız Teknik Üniversitesi, Fen Bilimleri Enstitüsü, İstan bul.

Çebi, S., Özkök, M., Kafalı, M. ve Kahraman, C. (2016). A fuzzy multiphase and multicriteria decision-making method for cutting technologies used in Shipyards. International Journal of Fuzzy Systems, 18(2), 198-211.

Çelik, M., Kahraman, C., Çebi, S. ve Er, I. D. (2009). Fuzzy axiomatic design-based performance evaluation model for docking facilities in shipbuilding industry: The case of Turkish shipyards. Expert Systems with Applications, 36(1), 599-615.

Çiçek, F. (2007). Kısa Mesafeli Yoğun Yolcu Taşımaya Yönelik Deniz Aracı Konsept Tasarımı ve İşlevsellik Yönünden Değerlendirilmesi, Yüksek Lisans Tezi, Yıldız Teknik Üniversitesi, Fen Bilimleri Enstitüsü, İstanbul.

Demirel, H. (2020). A novel fuzzy multi-criteria decision-making methodology based upon the spherical fuzzy sets for stabilizer selection of cruise ships. Brodogradnja: Teorija i praksa brodogradnje i pomorske tehnike, 71(3), 1-11.

Demirel, H., Şener, B., Yıldız, B. ve Balin, A. (2020). A real case study on the selection of suitable roll stabilizer type for motor yachts using hybrid fuzzy AHP and VIKOR methodology. Ocean Engineering, 217, 108125 .

Ebrahimi, A., Brett, P. O. ve Garcia, J. J. (2018). Managing complexity in concept design development of cruise-exploration ships. In Marine Design XIII (pp. 569-577). CRC Press.

Erdem, T. (2002). Savaş Gemilerinin Maliyetlerinin Azaltılmasında Bilgi Yönetimi, Yüksek Lisans Tezi, İstanbul Teknik Üniversitesi, Fen Bilimleri Enstitüsü, İstanbul.

Erol, A. (2014). Tersanelerde İmalatı Yapılacak Gemi Tipinin Bulanık TOPSIS ve Bulanık VIKOR Yöntemleri İle Belirlenmesi, Yüksek Lisans Tezi, Yıldız Teknik Üniversitesi, Fen Bilimleri Enstitüsü, İstanbul. 
Güler, O., I. (2020) Gemi İnşa Projelerinde PLM Yazılımı Seçimi, Yüksek Lisans Tezi, Bahçeşehir Üniversitesi, Fen Bilimleri Enstitüsü, İstanbul.

Güneri, A. F., Cengiz, M. ve Şeker, S. (2009). A fuzzy ANP approach to shipyard location selection. Expert systems with applications, 36(4), 7992-7999.

Huber, S., Geiger, M. J. ve de Almeida, A. T. (2019). Multiple Criteria Decision Making and Aiding. Springer International Publishing.

Ishizaka, A. ve Labib, A. (2009). Analytic hierarchy process and expert choice: Benefits and limitations. Or Insight, 22(4), 201-220.

İnal, O. B. ve Deniz, C. (2020). Assessment of fuel cell types for ships: Based on multi-criteria decision analysis. Journal of Cleaner Production, 265, 121734.

Jafaryeganeh, H., Ventura, M. ve Soares, C. G. (2020). Application of multi-criteria decision making methods for selection of ship internal layout design from a Pareto optimal set. Ocean Engineering, 202, 107151.

Jeong, B., Oguz, E., Wang, H. ve Zhou, P. (2018). Multi-criteria decision-making for marine propulsion: Hybrid, diesel electric and diesel mechanical systems from cost-environment-risk perspectives. Applied Energy, 230, 1065-1081.

Kafalı, M. (2014). Gemi İnşa Sanayinde Bulanık Karar Verme Uygulamaları, Yüksek Lisans Tezi, Karadeniz Teknik Üniversitesi, Fen Bilimleri Enstitüsü, Trabzon.

Kafalı, M., Özkök, M. ve Çebi, S. (2014). Evaluation of pipe cutting technologies in shipbuilding. Brodogradnja: Teorija i praksa brodogradnje i pomorske tehnike, 65(2), 33-48.

Kafalı, M. ve Özkök, M. (2015). Evaluation of shipyard selection criteria for shipowners using a fuzzy technique. Journal of Marine Engineering \& Technology, 14(3), 146-158.

Kahvecioğlu, G. A. (2021). Gemi İçin Balast Suyu Arıtma Sisteminin Belirlenmesi, Yüksek Lisans Tezi, Lisansüstü Eğitim Enstitüsü, İstanbul.

Keçeci, T. (2010). İstanbul Boğazı'nda Gemi Boyu Faktörünün Güvenli Seyre Etkisinin AHP Metodu Kullanılarak Analiz Edilmesi, Yüksek Lisans Tezi, İstanbul Teknik Üniversitesi, Fen Bilimleri Enstitüsü, İstanbul.

Keeney, R. L., Raiffa, H. ve Meyer, R. F. (1993). Decisions with multiple objectives: preferences and value trade-offs. Cambridge University Press.

Kırdağlı, M. (2010). Tersanelerde Verimliliği Etkileyen Parametrelerin Fuzzy AHP Yöntemi ile Analizi, Doktora Tezi, İstanbul Teknik Üniversitesi, Fen Bilimleri Enstitüsü, İstanbul.

Köksalan, M. M., Wallenius, J. ve Zionts, S. (2011). Multiple criteria decision making: From early history to the 21st century. Singapore: World Scientific.

Lazakis, I. ve Ölçer, A. (2016). Selection of the best maintenance approach in the maritime industry under fuzzy multiple attributive group decision-making environment. Proceedings of the Institution of Mechanical Engineers, Part M: Journal of Engineering for the Maritime Environment, 230(2), 297-309. 
Maes, M. ve Faber, M. (2004) Issues in utility modeling and rational decision making, in Proceedings of 11th IFIP WG 7.5 Reliability and Optimization of Structural Systems (eds M. Maes and L. Huyse), Balkema Publishers, London.

Mardani, A., Jusoh, A., Nor, K., Khalifah, Z., Zakwan, N. ve Valipour, A. (2015). Multiple criteria decisionmaking techniques and their applications-a review of the literature from 2000 to 2014. Economic research-Ekonomska istraživanja, 28(1), 516-571.

Mardani, A., Jusoh, A. ve Zavadskas, E. K. (2016). Fuzzy multiple criteria decision-making techniques and applications-Two decades review from 1994 to 2014. Expert Systems with Applications, 42(8), 4126-4148.

Matulja, T., Fafandjel, N. ve Zamarin, A. (2009). Methodology for shipyard production areas optimal layout design. Brodogradnja: Teorija i praksa brodogradnje i pomorske tehnike, 60(4), 369-377.

Menteş, A. (2000). Manevra ve Sevk Sistemi Seçiminde Bulanık Çok Kriterli Karar Verme, Yüksek Lisans Tezi, İstanbul Teknik Üniversitesi, Fen Bilimleri Enstitüsü, İstanbul.

Menteş, A. (2010). Açık Deniz Yapıları Bağlama Sistemlerinin Dizaynında Bulanık Çok Kriterli Karar Verme Yöntemlerinin Uygulanması, Doktora Tezi, İstanbul Teknik Üniversitesi, Fen Bilimleri Enstitüsü, İstanbul.

Mytilinou, V., Lozano-Minguez, E. ve Kolios, A. (2018). A framework for the selection of optimum offshore wind farm locations for deployment. Energies, 11(7), 1855.

Ölçer, A. İ. (2001). Yeni Bir Bulanık Çok Öz-Nitelikli Karar Verme Tekniğinin Geliştirilmesi ve Gemi İnşaatı ve Dizaynı Karar Verme Problemlerine Uygulanması, Doktora Tezi, İstanbul Teknik Üniversitesi, Fen Bilimleri Enstitüsü, İstanbul.

Ölçer, A. İ., Tuzcu, C. ve Turan, O. (2006). An integrated multi-objective optimisation and fuzzy multiattributive group decision-making technique for subdivision arrangement of Ro-Ro vessels. Applied Soft Computing, 6(3), 221-243.

Ölçer, A. İ. ve Odabaşı, A. Y. (2005). A new fuzzy multiple attributive group decision making methodology and its application to propulsion/manoeuvring system selection problem. European Journal of Operational Research, 166(1), 93-114.

Paksoy, A. (1998). Çok Amaçılı Karar Ortamında Gemi Seçimi Modeli, Doktora Tezi, İstanbul Üniversitesi, Fen Bilimleri Enstitüsü, İstanbul.

Ross, T. J. (2004). Fuzzy logic with engineering applications (Vol. 2). New York: Wiley.

Roszkowska, E. (2011). Multi-criteria decision making models by applying the TOPSIS method to crisp and interval data. Multiple Criteria Decision Making/University of Economics in Katowice, 6(1), 200-230.

Saraçoğlu, B. Ö. (2009). Büyük Yatırım Analizlerinde Yeni Genel Bir Yöntem ve Tersane- Liman Yatırımında Bir Uygulama, Doktora Tezi, İstanbul Teknik Üniversitesi, Fen Bilimleri Enstitüsü, İstanbul.

Triantaphyllou, E. (2000). Multi-criteria decision making methods: a comparative study. Springer, Boston, MA. 
Türk, A. ve Özkök, M. (2020). Shipyard location selection based on fuzzy AHP and TOPSIS. Journal of Intelligent \& Fuzzy Systems, (Preprint), 1-20.

Uzun, S. (2015). Gemi İnşa Sürecinde Ana Makine ve Jeneratör Seçimi: AHP, TOPSIS, PROMETHEE Uygulaması, Yüksek Lisans Tezi, Gebze Teknik Üniversitesi, Sosyal Bilimler Enstitüsü, Kocaeli.

Ünver, B. (2017). Gemi Dizel Makinelerinde Yapılan Bakım Onarım Çalışmalarına Yönelik Bulanık Mantık Temelli Risk Değerlendirmesi, Yüksek Lisans Tezi, Karadeniz Teknik Üniversitesi, Fen Bilimleri Enstitüsü, Trabzon.

Yang, Z. L., Zhang, D., Caglayan, O., Jenkinson, I. D., Bonsall, S., Wang, J., ... ve Yan, X. P. (2012). Selection of techniques for reducing shipping NOx and SOx emissions. Transportation Research Part D: Transport and Environment, 17(6), 478-486.

Yaraş, S. (1999). Gemi Ana Makine Seçiminde Çok Kriterli Karar Verme Yöntemlerinin Uygulanması, Yüksek Lisans Tezi, İstanbul Teknik Üniversitesi, Fen Bilimleri Enstitüsü, İstanbul.

Zangoueinezhad, A., Azar, A. ve Kazazi, A. (2011). Using SCOR model with fuzzy MCDM approach to assess competitiveness positioning of supply chains: focus on shipbuilding supply chains. Maritime Policy \& Management, 38(1), 93-109.

Zapata Cortés, J. A., Arango Serna, M. D. ve Adarme Jaimes, W. (2012). Applying fuzzy extended analytical hierarchy (FEAHP) for selecting logistics software. Ingeniería E Investigación, 32(1), 94-99.

Url-1 <https://en.wikipedia.org/wiki/Multiple-criteria_decision_analysis> 11.10.2021

Url-2 <https://tr.wikipedia.org/wiki/Yöneylem_araştırması 14.10.2021

Url-3 <https://en.wikipedia.org/wiki/Analytic_hierarchy_process> 14.10.2021

Url-4 <https://en.wikipedia.org/wiki/TOPSIS> 14.10.2021 